\title{
Narrative-Driven Immersion and Students' Perceptions in an Online Software Programming Course
}

\author{
Mario Madureira Fontes \\ Universidade Aberta, Coimbra, Portugal \\ PUCSP, São Paulo, Brasil \\ 0000-0002-5618-0616 \\ Ceres Morais \\ INESC TEC, Porto, Portugal \\ UERN, Mossoró, Brasil \\ 0000-0001-6270-2508 \\ Leonel Morgado \\ INESC TEC, Porto, Portugal \\ Universidade Aberta, Coimbra, Portugal \\ 0000-0001-5517-644X
}

\author{
Daniela Pedrosa \\ Univ. Aveiro, CIDTFF, Aveiro, Portugal \\ UTAD, Vila Real, Portugal \\ 000-0001-9536-4234 \\ Aline Costa \\ Univ. do Porto e INESC-TEC \\ Porto, Portugal \\ 0000-0002-3851-3421
}

\author{
Tânia Araújo \\ Universidade de Aveiro \\ Aveiro, Portugal \\ 0000-0002-6434-6735
}

\author{
José Cravino \\ CIDTFF, Aveiro, Portugal \\ UTAD, Vila Real, Portugal \\ 0000-0002-5376-6128
}

\begin{abstract}
Learning software programming is challenging for software engineering students. In this paper, students' engagement in learning software engineering programming is considered under the SimProgramming approach using the OC2-RD2 narrative technique to create an immersive learning context. The objectives of this paper are twofold: presenting a narrative-driven immersive learning approach to introduce software engineering concepts and coding techniques to online undergraduate students; and analyzing the students' feedback on this approach. Thematic analysis of the metacognitive tasks was performed on the students' fortnightly reflections about their learning progress. Content analysis was based on interest categories, students' perceptions, metacognitive challenges, narratives, examples and aspects to be kept or to be improved. Data from the content analysis were organized into categories, subcategories, indicators, and recording units and their categorization was peer-reviewed. The narratives were considered by the students as interesting, appealing, akin to professional reality and promoting interaction. Most students thought the approach was helpful for learning software programming.
\end{abstract}

Index Terms - teaching methods, student surveys, distance education, computer science education, learning processes

The knowledge and skills a software engineer must master comprise: resilience; maintainability; adaptability; knowledge of theoretical approaches and design methods; technology and tools; recognizing, understanding, modelling, formalizing and analyzing new problems; adapting known solutions; managing an organizational process; interacting with people and coordinating the work of different people [1]-[3]. A survey of 1,926 experts recommended requirements for software engineers' professional performance [2]: writing good code; adjusting behaviors to account for future values and costs; practicing informed decision-making, avoiding making other people' $\mathrm{s}$ jobs harder; and learning continuously.

An aspect where software engineering students face significant challenges developing these skills and knowledge is learning large-scale computer programming techniques. It involves combining abstract theoretical concepts of software quality, advanced coding techniques, and anticipating human and systemic problems and risks. Rather than focus on making a piece of software work, software engineering cares about aspects such as robustness and reliability of development, and the end-product adaptability to changes in requirements, circumstances, and similar abstract scenarios.

This prospective nature of the learning objectives of software engineering raises the need to challenge and motivate students for their learning. In this paper, we consider the immersion dimensions of narrative and challenge [4], to explore the use of narrative to drive immersion by supporting students' engagement in learning software engineering programming under the SimProgramming didactic approach [3], [5]-[10]. SimProgramming is a teaching approach concerned with providing a fruitful learning environment, self-and co-regulated forms of learning and formative assessment processes.

The narrative-driven immersion was approached using the educational narrative development technique OC2-RD2, described in section II.

The objectives of this paper are twofold: presenting a narrative-driven immersion approach to introduce software engineering concepts and coding techniques to online undergraduate students; and analyzing the students' feedback on this approach. 


\section{BACKGROUND}

The OC2-RD2, formerly OCC-RDD, is a technique for creating educational narratives and their instructional use [11] [18]. The acronym parts stand for Objective, Complication, Catastrophe (OCC or OC2), and Reaction, Dilemma and Decision (RDD, RD2). The OC2 part introduces a third person narrative, while the RD2 is a first person narrative, where characters themselves tell their story through dialogues. The technique includes character archetypes: Fubã, Fê, Ocara, Spec, Mestre Lum, and Naum Q. Kaow, with personalities described as social and psychological features (see. Table I).

The narratives developed with the OC2-RD2 technique introduce challenges, generating an engagement-focused learning environment whose dynamics encompass interactive roles among the actors (characters, learner, teacher) and the conceptual frameworks of the fields of knowledge under focus. Its positive impact on the learning of computational concepts and programming and its affinity with interactive learning methods have been affirmed [16]-[18].

In contact with the characters via the narratives, students engage in an immersive experience within the narrative (narrative immersion) and outside it (challenge immersion). When reading the narrative, the learner establishes a connection between the imagery generated by the story and the real world (its personal story) [12], [16]-[18].

The structure of the OC2-RD2 narrative technique comprises a narrative, its script, the characters, the places and settings of the narrative plot and the actions involving characters and settings (Fig. 1).

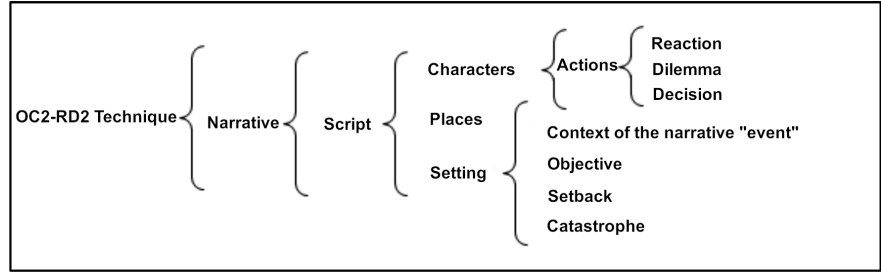

Fig. 1. Structural elements of the OC2-RD2 narrative technique. Scheme adapted from Rosa et al. [16].

\section{THE OC2-RD2 CHARACTERS: ADAPTATIONS AND NEWNESS}

This OC2-RD2 approach was applied at a 2nd-year course in the fully online Informatics Engineering Undergraduate Programme at Universidade Aberta (UAb) in Portugal: "Software Development Laboratory" (LDS, Portuguese-language acronym). The online e-learning format was asynchronous, using the Moodle platform, over the 2nd semester of the 20192020 academic year (12 academic weeks). The course goal is to scaffold undergraduates transitioning from novice programmers into proficient programmers, over a six-topic syllabus covering the Model-View-Controller architectural style and its implementation in coding for various libraries, frameworks, and APIs, following principles such as low coupling and high cohesion. Thirty-two students accepted to participate in this study.

The student cohort is heterogeneous in age (research participants ranged from 25 to 60 years old), gender, location (different regions of the country and abroad), and educational level (a mix of secondary education, some college attendance, and undergraduate degrees in fields other than computing), and already part of the workforce. The asynchronous mode means no specific hours are scheduled for activities, but rather deadlines within a date span, as mandated by UAb's pedagogic model. In each topic, activities include forum discussions with the teaching staff and colleagues, also asynchronously. Students' age span and occupations imply scheduling constraints of active professional careers and the need to care for children or older relatives. Being disseminated across the globe, students deal with varying time zones: small teams can arrange to meet, but there is no live lecturing schedule that would fit all.

The original characters in OC2-RD2 [17] were adapted to the SimProgramming didactic approach followed in the course [3], [5]-[10], which employs situated learning in business-like context, and to the students' profiles (the overwhelming majority were from Portugal). This meant renaming characters with nicknames more connected to Portugal's cultural and business reality rather than Brazil's. It also meant rendering them as professional colleagues, rather than teachers or students (see Table I). Further, we corrected the gender imbalance of the original character set. This led to impacts on their original personality traits (see Table I).

To develop the OC2-RD2 narratives for the LDS course, for each of the six syllabus topics, the process was organized into five stages: first, identifying the educational goals according to the cognitive process and knowledge dimensions of Bloom's taxonomy [22]; second, organizing those goals by matching them to OC2 scenes - Objective, Complication, and Catastrophe; third, outline narratives for the dialogues and character actions defined by RD2 (Reactions, Dilemmas, and Decisions), as well as complementary narratives to maintain narrative immersion when presenting to students the tasks and support materials; fourth, checking for any resulting goal overlapping or gaps; and fifth, final drafting of the narratives and their transposition to the Moodle platform.

\section{EXAMPLES OF NARRATIVES WITHIN THE SimProgramming FrameWORK}

This section exemplifies the narratives presented to the students of the LDS course. Narrative 1 focuses on the importance of the concepts of low coupling between components when using APIs and Narrative 2 is an example of metacognition support via a questionnaire eliciting student recall of personal perspectives about using software engineering techniques.

The narratives herein are translated from their original written form in European Portuguese.

\section{A. Narrative 1}

The example below, retrieved from topic 3 of the course syllabus, shows a narrative where characters interact with 
TABLE I

DESCRIPTION OF CHARACTERS' SOCIAL AND PSYCHOLOGICAL TRAITS

Original character OC2-RD2 [19]: Mestre Lum

Adapted Portuguese Character: Boss

Adapted character archetype description: Manager who provides instructions and guidance. The English-language word "boss" is often used informally in this context in Portugal as a nickname by which subordinates refer to their manager.

Personality traits [20], [21]: "willing to share at the personal and professional level"; Extraversion: high; Agreeableness, Conscientiousness, Neuroticism, and Openness: average.

Original character OC2-RD2 [19]: Fubã

Adapted Portuguese Character: Meiabola

Adapted character archetype description: An employee prone to snap decisions, often recklessly. The name stems from the popular expression "Meia bola em força" (lit. "half a ball with imparted strength").

Personality traits [20], [21]: "skilled and capable for any task, performed in accordance with previous training and preparation". Neuroticism, Extraversion, Agreeableness, and Openness: low; Conscientiousness: high.

Original character OC2-RD2 [19]: Ocara

Adapted Portuguese Character: Patavinas

Adapted character archetype description: A good-spirited colleague eager to provide support, even if the contributions are not entirely reliable. This nickname is the plural of a popular Portuguese-language word meaning "nothing", often used as "clueless".

Personality traits [20], [21]: "tends to be an ideas salesperson". Neuroticism and Conscientiousness: low; Extraversion and Agreeableness: average; Openness: low.

Original character OC2-RD2 [19]: Spec

Adapted Portuguese Character: Ada

Adapted character archetype description: A knowledgeable employee, who is keen on providing guidance and contributing to management's goals. The name is a tribute to Ada Lovelace.

Personality traits [20], [21]: "generally articulate, fluent, and persuasive communication". Neuroticism: low; Extraversion: high; Agreeableness and Conscientiousness: average; Openness: low.

Original character OC2-RD2 [19]: Fê

Adapted Portuguese Character: Fezada

Adapted character archetype description: An employee focused on developing team bonding, consistently encouraging team collaboration and communication. This nickname means "Sure bet" or "strong conviction" (lit. "somewhat big faith").

Personality traits [20], [21]: "a person generally able to get involved with those around, becoming a net value to the surroundings, both personally and professionally".

Neuroticism and Agreeableness: average; Extraversion and Conscientiousness: high; Openness: low.

Original character OC2-RD2 [19]: Naum Q. Kaow

Adapted Portuguese Character: Catmming

Adapted character archetype description: Artificial intelligence character who challenges students to reflect through metacognitive tasks. Unlike the other characters, the name Catmming does not result from a traditional Portuguese popular expression. It is the name of a wordplay association: the first part "Cat", the popular household pet, because it's an animal with an independent and challenging personality; the second part results from a pun on Programming ("mming").

Personality traits [20], [21]: "keen on details, especially those that may impact results".

Neuroticism, Extraversion, Agreeableness: average Conscientiousness: high; Openness: high.

each other and with the students, taking into consideration the following Bloom's dimensions: Factual Knowledge, in the Remembering process (to minimize coupling, students have to remember concepts related to component coupling); Procedural Knowledge, in the Applying process (to develop students' awareness of the importance of implementing low coupling among components); Factual, Conceptual, and Pro- cedural Knowledge, in the Creating process (coding with low coupling among components).

Boss: Hi guys!! Feeling fine?! How is that demo app development going?

Meiabola: Everything's alright, Boss. I'm making one with Patavinas. We've got our ideas in shape, drew the preliminary structural diagrams, and started coding this stuff, so that we can discuss it later on. Ada: Likewise. We are in sync. I'm making one with Fezada and we have been checking up with with Meiabola and Patavinas, sharing our thoughts.

[Sequence diagrams from the apps of both teams are shown in the narrative here]

Boss: Excellent! Since you are already coding, don't forget about our internal SimProgramming strategy: minimize component coupling. That must impact your demo apps. Are the ones you're coding already good examples of that or not?

Patavinas: But... weren't we just supposed to showcase what the company could do with these new APIs?

Boss: Yes, showcase it, Patavinas, but that's no mere "just"... For our company to be efficient, whatever is made with those APIs must have a way of aligning with our global development strategy. And that means low component coupling.

$<$ awkward silence $>$

Boss: Uhm... Look, Meiabola and Patavinas, Ada and Fezada, and all other teams: I assume your silence means you were not considering this aspect. So, each of you check if the coding you're using for your demo app is a good example of low component coupling. An example fit to be part of SimProgramming's development strategy!

So go on, check it. In a few days I'll be back to catch up on your status.

$<$ Each team picks its case: code and diagram, unsure of what to look for.>

In summary, this narrative aims to raise learner awareness about the importance of low component coupling, and of coding strategies' as impacting company adoption of a new API.

\section{B. Narrative 2}

The following narrative, from topic 1 of the course syllabus, has a single character, Catmming. It is an example of introducing metacognitive tasks immersively, following Bloom's "Metacognitive" knowledge dimension, and "Remember" cognitive process. By having students check whether their personal perspectives changed regarding the value of using software engineering techniques, its goal is to make them realize that the use of such techniques is indeed relevant for software development.

Catmming: Knock, knock.

Hey guys! 
Many factors must be considered in the software development process! Are you able to develop software with engineering principles in mind? Did your way of thinking about software development change after analyzing the post-mortems? Does the way in which software is developed impact its progress?

Let's think about it!

After reading this narrative, students had to answer a set of questions (test format - a Moodle feature) about their self-concept as programmers and their reflections about the software development process. In this example, one of the questions asked was: "What is my level of awareness about the importance of engineering techniques in software development?" To answer, students select an alternative from a Likert scale (Very Low; Low; Median; High; or Very high). After choosing, students were asked to explain their choice.

\section{RESUlts AND Discussion}

We analyzed the metacognitive tasks (MT8, 12, 15, 17, and partially 20) based on students' fortnightly reflections (FR) about their learning progress using thematic analysis [23]. Content analysis matrices were based on interest categories and students' perceptions on the following: 1) metacognitive challenges posed by Catmming character; 2) narratives and examples; and 3) aspects to be kept or to be improved.

Data from the content analysis was organized into categories, subcategories, indicators, and recording units (snippets of sentences) as they emerged from the analysis by two researchers. Then, a cyclical process of improvement, synthesis, and reflection was conducted with two more researchers.

Throughout the metacognitive tasks, particularly in the fortnightly reflections (Metacognitive Tasks 8, 12, 15 and 17, comprising the 1 st through 5 th fortnightly reflections), we observed that students included in their critical reflections on their learning progress some perceptions related to the SimProgramming narratives and characters.

We categorized these students' perceptions under four subcategories: 1) immersion in the narratives; 2) perceptions about the positive impact of narratives on their learning process; 3 ) narrative aspects that needed to be improved; and 4) negative perceptions.

Regarding narrative immersion (subcategory 1), students $(n=9)$ incorporated situated learning in their reflections, through aspects associated with being part of the SimProgramming company and viewing the characters as real colleagues/managers:

"(...) The colleagues who were already here have been of great help, and I confess that it is an honor to be in the same company as Ada. (...)" S47, 03/14/2020 (MT8 - FR1)

"(...) I dedicated myself to complying with the procedures required by the company. (...) I managed to carry out all the tasks requested by the Boss (...)." S53, 04/04/2020 (TM12 - RF2)

"(...) in a project with my colleagues. The dialogues helped maintain that perception (...)." S6, 6/3/2020

(Tm15 - RF3)

Regarding the positive impacts of the narratives (subcategory 2$)$, the students found them interesting $(n=3)$ :

"(...) Because this work method is very interesting and motivating. "S34, 04/04/2020 (MT8 - FR1)"

They also considered that the narratives supported task awareness $(\mathrm{n}=10)$ :

"It has been helpful how "colleagues" have moved into that direction. (...) And references and collaboration from "colleagues" have been useful. "S44, 3/21/2020 (MT8 - FR1)

“(...) I'm adapting quite well to the way SimProgramming works. The examples help my work a lot.'S47, 13/04/2020 (MT12 - FR2)

They found them to be fun $(n=1)$ :

"The concept of SimProgramming is somewhat funny." S59, 03/22/2020 (Tm8 - RF1)

They found it akin to professional reality $(n=5)$ :

"(...) The characters are a good simulation of real people, and help to create the illusion that one is in a real company." S36, 4/13/2020 (MT8 - FR1)

"(...) In the same way that I imagine it would go if, in reality, it occurred in an organization with some teammates having a collaborative attitude that helped to internalize the organizational culture. "S6, 04/04/2020 (MT8 - FR1)

Regarding the narrative aspects that need improvement (subcategory 3), students reported difficulties interpreting the narratives: being confused $(n=1)$; reading comprehension $(n=2)$, and lack of task completion awareness $(n=2)$, e.g.:

"The way the content was provided so far makes it difficult to understand what one is supposed to do in the activities" S38, 25/03/2020 (MT8 - FR1)

"Also, the interpretation of texts (...)" S56, 05/04/2020 (TM12 - RF2)

"The main difficulty has been the ability to find where I am (...) I end up getting lost and constantly retracing my steps." S56, 04/04/2020 (MT8 - FR1)

Regarding negative perceptions (subcategory 4), one student expressed conflicts with his personal preferences:

"My introverted nature prevents me from making this type of integration without difficulties. I can even say that I am not a fan of any employee of the company, however friendly they seem to be. (...)" S57, 03/21/2020 (MT8 - FR1)

When students were asked directly about the narratives, in Metacognitive Task 20 (in the 6th fortnightly reflection, MT20FR6), they expressed the following views on Catmming's metacognitive challenges and on the fortnightly reflections: difficulties completing the challenges (view 1); the metacognitive challenges are innovative (view 2); the approach is motivating (view 3); they felt the narratives helped them develop self-regulation learning strategies (view 4); and various improvement suggestions (view 5). 
Three students were unable to complete the challenges due to: lack of time because of professional demands $(n=1)$; time management difficulties associated with the COVID-19 pandemic $(n=1)$; and unspecified time management difficulties $(\mathrm{n}=1)$ :

"Professional work often interrupts what is necessary to be able to complete the challenges posed." S8, 5/30/2020 (Tm20 - RF6)

"The fact of being confined home since March 13th has made me lose track of time, even on weekdays". (S56, 06/01/2020, Tm20 - RF6)

"I confess that I was unable to manage my work time very well (...)" S6, 06/08/2020 (MT20 - FR6)

One student mentioned metacognitive challenges as innovative and allowing one to go beyond readings $(n=1)$ :

"The organization in sprints is a new and innovative way of approaching (...) seems very appropriate and motivating to me, since it doesn't just send us to pages in a book." S1, 6/1/2020 (MT20 - FR6)

Catmming's challenges were also mentioned as a motivating approach because it allows them to monitor the development of their tasks $(n=3)$ :

"It keeps pace with our own development." S1, 6/1/2020 (Tm20 - RF6)

"(...) the sprints were good to understand the point of situation (...)" S53, 06/04/2020 (Tm20 - RF6)

"(...) they gave clues to the next challenges." S54, 06/07/2020 (Tm20 - RF6)

It allows them to feel that there is an evolution at work $(\mathrm{n}=1)$ :

“(...) Catming's challenges (...) were always presented in such a way that it felt a" natural "evolution of the themes. S54, 06/07/2020 (Tm20 - RF6)

They considered Catmming's challenges interesting $(n=2)$ :

"I found all the challenges quite interesting (...)" S53, 06/04/2020 (Tm20 - RF6)

"Catmming's challenges are interesting (...)" S54, 06/07/2020 (Tm20 - RF6)

And that it is an appropriate approach:

"It seems very appropriate and motivating (...)" S1, 01/06/2020 (Tm20 - RF6)

The metacognitive challenges help in the development of self-regulation learning strategies, such as reflection about work done $(n=1)$ :

"The biweekly reflections help me to understand how I managed to deal with the proposed challenges (...)"S54, 07/06/2020 (Tm20 - RF6)

And at the organization level $(n=2)$ :

"(...) the sprints were good for (...) reorganizing."

S53, 06/04/2020 (Tm20 - RF6)

"(...) organize my work." S54, 06/07/2020 (Tm20 -

RF6).
However, there was one student who considered that an aspect to be improved would be the integration of other multimedia elements $(n=1)$ :

“(...) I missed some support from videos to help me.” S52, 06/03/2020 (Tm20 - RF6)

Regarding the opinions that students have about the narratives and examples used by the SimProgramming company, two dimensions of perceptions are found: 1) positive opinions about the impact that narratives had on their learning and 2) aspects to improve.

The students mentioned as positive aspects of the narratives, namely, that they were interesting $(n=2)$ :

"I found it very interesting (...)" S34, 05/31/2020 (Tm20 - RF6)

"I feel they are very interesting (...)" S6, 06/08/2020 (Tm20 - RF6)

Students liked the experience $(n=2)$ :

"I liked the adopted approach." S8, 5/30/2020 (Tm20

- RF6)

"I really enjoyed the experience of this course (...)" S53, 06/04/2020 (Tm20 - RF6)

They are innovative and original $(n=2)$ :

"It is a very innovative way of approaching concepts (...)" S1, 01/06/2020 (Tm20 - RF6)

"I really enjoyed the experience of this very original UC (...)" S53, 06/04/2020 (Tm20 - RF6)

On the fact that the strategy could be applied to other courses $(n=1)$ :

"This type of strategy could well try to be applied in other curricular units." S1, 6/1/2020 (Tm20 - RF6)

Helpful in guiding the work to be carried out $(n=1)$ :

"(...) they end up helping to enter the development scheme. In fact, the dialogues were an asset helping to understand what was requested. "S6, 06/08/2020 ( Tm20 - RF6)

It helped provide a picture of what software development is $(\mathrm{n}=1)$ :

"(...) gives us a small view of the software development world." S53, 06/04/2020 (Tm20 - RF6)

Finally, a student considered the narratives to be interactive, i.e. originating engagement with the tasks $(n=1)$ :

“(...) becoming more appealing through interactivity.

(...)" S1, 06/01/2020 (Tm20 - RF6)

However, some students reported aspects to be improved and difficulties they experienced with the narratives, such as the lack of complementary feedback $(n=1)$; being confusing $(n=2)$; making it difficult to concentrate $(n=1)$ and the examples not being entirely adjusted to reality $(n=1)$.

"(...) I felt very disappointed and not sure if what I am doing is correct. " S34, 5/31/2020 (Tm20 RF6)

"Some have become very confused." S56, 06/01/2020 (Tm20 - RF6) 
"It's a bit confusing, especially in the videos and that weird narrative with interpreters from the other world..."S54, 06/07/2020 (Tm20 - RF6)

"It doesn't help concentration." S54, 06/07/2020 (Tm20-RF6)

"Ideologically it's very good, but I think it would be easier if they were more suitable to reality."S56, 06/01/2020 (Tm20 - RF6)

From the analysis of the students' statements as those above, we deduce that the narratives written with the OC2-RD2 technique were found to be appealing, interesting, innovative, suitable, promoting enriching experience, increasing interactivity and helping software development learning. They helped students immerse themselves in a simulated business narrative and its challenges, as well as reflect on their learning progress. Most students thought the dialogues were helpful towards the development of their software.

The fact that the narratives were considered appealing, interesting, and promoting an enriching experience can be interpreted as related to their constituent structure which motivates learners because they include characteristics (Objective, Complication, Catastrophe, Reaction, and Dilemma) which engage readers into the narrative plots. However, it is necessary to understand what are the actual effects of these characteristics on the students' learning progress.

Also, the fact that the narratives were pointed out as suitable for learning, suggests that the information presented in the dialogues of the narratives was adequate to help learners start to understand the process of large-scale software development. Nevertheless, there have also been students reporting that narratives match to reality could be improved.

Finally, the perception that the narratives promote interactivity can be related to the possibilities of interaction among participants (characters, teacher and learners). In future work, we recommend analyzing how this interactivity contributes to self-regulated and co-regulated learning.

Some students reported difficulties interpreting the narratives, and lacking complementary feedback. It is also important to find alternative approaches for students who, due to personal characteristics, find it difficult to manage the narrative plots, resulting in a psychological effect contrary to the one intended (e.g. S57).

The limitations of this work concern the analysis of students' perceptions without triangulation with other data. However, test reliability has been ensured since the testing process was reviewed by multiple project researchers through peer review.

\section{CONCLUSION}

Throughout the course, particularly in the fortnightly reflections, students demonstrated they were immersed in the narratives and in the challenges. Students used expressions such as "my colleagues", "boss" in their reflections as if the characters were real and mentioned that they were really integrated into the tasks of the SimProgramming "company".
We conclude from the analysis of the students' perceptions that the introduction of metacognitive challenges by the character Catmming in the narrative scenes was innovative and motivational, contributing to help students better understand their work progress and develop self-regulation learning strategies related to the organization of their study and to their awareness and reflection skill.

Some students reported difficulties carrying out the Catmming challenges, mostly related to time management due to professional and personal lives, in some cases explicitly explained as arising from the COVID-19 pandemic.

The same type of perceptions were found in relation to the narratives of the other characters (Ada, Fezada, Meiabola and Patavinas). The students considered the experience innovative and original, and that it contributed to the development of self-regulation learning strategies such as: guiding their work, understanding the technical tasks associated with software development, and promoting links with professional reality.

In future work, we recommend improving narratives considering the suggestions given by the students, such as: integrating other multimedia elements; complementing narratives with feedback (to avoid the students loosing track of where they are in their learning progression); improving clarity of dialogues (some were considered confusing, or hard to follow). We are considering as alternative media for future improvements, pending review of literature recommendations: digital cartoons, e-comics, videos, podcasts, and tools for observational research.

Furthermore, it is necessary to design strategies that allow students to easily find where they stand in their learning progression, to know what they have already accomplished and studied and/or to identify which aspects of study and work are still missing.

It is also important to outline alternative pathways for students who do not appreciate these narratives to be able to carry out the course tasks regardless.

\section{ACKNOWLEDGMENTS}

This work is financially supported by National Funds through FCT - Fundação para a Ciência e a Tecnologia, I.P., under project PTDC/CED-EDG/30040/2017.

Daniela Pedrosa wishes to thank Fundação para a Ciência e Tecnologia (FCT) and CIDTFF (UID/CED/00194/2019) Universidade de Aveiro, Portugal, for Stimulus of Scientific Employment - CEECIND/00986/2017 Individual Support 2017.

We would like to thank all the students and teachers who collaborated on this research.

\section{REFERENCES}

[1] C. Ghezzi and D. Mandrioli, "The challenges of software engineering education," in Software Engineering Education in the Modern Age, ser. Lecture Notes in Computer Science, P. Inverardi and M. Jazayeri, Eds. Springer, pp. 115-127.

[2] P. L. Li, "What makes a great software engineer," accepted: 2016-0922T15:46:46Z. [Online]. Available: https://digital.lib.washington.edu: 443/researchworks/handle/1773/37160 
[3] D. Pedrosa, L. Morgado, J. Cravino, M. M. Fontes, M. Castelhano, C. Machado, and E. Curado, "Challenges implementing the SimProgramming approach in online software engineering education for promoting self and co-regulation of learning," in 2020 6th International Conference of the Immersive Learning Research Network (iLRN). IEEE, pp. 236-242. [Online]. Available: https://ieeexplore.ieee.org/document/9155183/

[4] L. Morgado and D. Beck, "Unifying protocols for conducting systematic scoping reviews with application to immersive learning research," in 2020 6th International Conference of the Immersive Learning Research Network (iLRN). IEEE, pp. 155-162. [Online]. Available: https://ieeexplore.ieee.org/document/9155093/

[5] D. Pedrosa, J. Cravino, L. Morgado, C. Barreira, R. R. Nunes, P. Martins, and H. Paredes, "SimProgramming : the development of an integrated teaching approach for computer programming in higher education," in INTED2016 Proceedings - 10th International Technology, Education and Development Conference March 7th-9th, 2016 - Valencia, Spain, L. Gómez Chova, A. López Martínez, and I. Candel Torres, Eds. IATED Academy, pp. 7162-7172. [Online]. Available: https://library.iated.org/view/pedrosa2016sim

[6] D. Pedrosa, J. Cravino, L. Morgado, and C. Barreira, "Self-regulated learning in computer programming: Strategies students adopted during an assignment," in Immersive Learning Research Network, C. Allison, L. Morgado, J. Pirker, D. Beck, J. Richter, and C. Gütl, Eds. Springer International Publishing, vol. 621, pp. 87-101. [Online]. Available: http://link.springer.com/10.1007/978-3-319-41769-1_7

[7] M. Chaves, "Abordagem SimProgramming : e-learning no ensino de programação em ambiente virtual." [Online]. Available: http: //hdl.handle.net/10400.2/7930

[8] D. Pedrosa, L. Morgado, and J. Cravino, "Abordagem eSimProgramming: primeiras alterações para implementação em contexto on-line e reflexões," in CNaPPES. 19-6. ${ }^{\circ}$ Congresso Nacional de Práticas Pedagógicas no Ensino Superior. Instituto Politécnico de Santarém, p. 50.

[9] D. Pedrosa, J. Cravino, L. Morgado, and C. Barreira, "Co-regulated learning in computer programming: Students co-reflection about learning strategies adopted during an assignment," in Technology and Innovation in Learning, Teaching and Education, M. Tsitouridou, J. A. Diniz, and T. A. Mikropoulos, Eds. Springer International Publishing, vol. 993, pp. 13-28. [Online]. Available: http://link.springer com/10.1007/978-3-030-20954-4_2

[10] R. R. Nunes, G. Cruz, D. Pedrosa, A. M. Maia, L. Morgado, H. Paredes, J. Cravino, and P. Martins, "Motivating students to learn computer programming in higher education: The SimProgramming approach," in Technology and Innovation in Learning, Teaching and Education, A. Reis, J. Barroso, J. B. Lopes, T. Mikropoulos, and C.-W. Fan, Eds. Springer International Publishing, vol. 1384, pp. 506-518, series Title: Communications in Computer and Information Science. [Online]. Available: https://link.springer.com/10.1007/978-3-030-73988-1_41

[11] M. M. Takeda, F. S. Marcondes, I. S. Vega, E. B. Gara, and L. Gaspar, "A computational teaching approach through the use of a narrative technique and a comic strip," in 2012 Ninth International Conference on Information Technology - New Generations. IEEE, pp. 445-451. [Online]. Available: http://ieeexplore.ieee.org/document/6209213/

[12] I. S. Vega, "Adaptive specifications and emotions: a model of narrative generation for interactive learning environments," vol. 13, no. 3, pp. 753 761. [Online]. Available: http://ieeexplore.ieee.org/document/7069101/

[13] M. M. Fontes and t. S. Vega, "A puzzle instructional framework for creating narratives with an OCC-RDD," in SBC - Proceedings of SBGames 2016, vol. 1. Simpósio Brasileiro de Games, pp. 1194-1197, issue: 1 .

[14] I. S. Vega, J. J. Neto, and F. S. Marcondes, "DInAton: A didactic and interative language for learning adaptive automata by construction," vol. 109, pp. 1176-1181. [Online]. Available: https://linkinghub.elsevier.com/retrieve/pii/S1877050917310682

[15] M. M. Fontes, "Gatilhos de desafios para o desenvolvimento de jogos e narrativas instrucionais." [Online]. Available: https://www.researchgate.net/publication/339698234_Gatilhos_de_ desafios_para_o_desenvolvimento_de_jogos_e_narrativas_instrucionais

[16] A. C. M. Rosa, K. Buttignon, I. S. Vega, and J. D. T Silva, "A practice of a narrative lesson model using fables based on the oc2-rd2 technique in the teaching of computer programming," vol. 3, no. 2, p. 253. [Online]. Available: http: //www.openaccessojs.com/index.php/JBReview/article/view/97
[17] K. Buttignon, t. S. Vega, J. d. T. Silva, and A. C. M. Rosa, A Técnica Oc2-Rd2 como uma Prática Metodológica para o Ensino de Programação de Computadores, $1 \mathrm{st}$ ed. Antonella Carvalho de Oliveira, pp. 137-148. [Online]. Available: https://www.atenaeditora.com.br/wp-content/uploads/2019/ 01/E-book-Princ\%C3\%ADpios-e-Aplica\%C3\%A7\%C3\%B5es-2.pdf

[18] W. Vendramel, H. Guirelli, and I. S. Vega, A Utilização de Estruturas Narrativas OC2-RD2 no Ensino de Computação: um Relato de Experiência, 1st ed. Atena Editora, pp. 107-115. [Online]. Available: https://www.atenaeditora.com.br/post-ebook/3475

[19] K. Buttignon, "Um protótipo de autoria de histórias OCC-RDD para ambientes de aprendizagem presencial." [Online]. Available: https://tede2.pucsp.br/handle/handle/18185

[20] R. R. McCrae and O. P. John, "An introduction to the five-factor model and its applications," vol. 60, no. 2, pp. 175-215. [Online]. Available: http://doi.wiley.com/10.1111/j.1467-6494.1992.tb00970.x

[21] B. Kort, R. Reilly, and R. Picard, "An affective model of interplay between emotions and learning: reengineering educational pedagogybuilding a learning companion," in Proceedings IEEE International Conference on Advanced Learning Technologies. IEEE Comput. Soc, pp. 43-46. [Online]. Available: http://ieeexplore.ieee.org/document/ $943850 /$

[22] D. R. Krathwohl, "A revision of bloom's taxonomy: An overview," vol. 41, no. 4, pp. 212-218. [Online]. Available: http://www.tandfonline. com/doi/abs/10.1207/s15430421tip4104_2

[23] V. Braun and V. Clarke, "Using thematic analysis in psychology," vol. 3, no. 2, pp. 77-101. [Online]. Available: http://www.tandfonline. com/doi/abs/10.1191/1478088706qp063oa 